\title{
BAKWITANAN: DESIGN OF A BLACKBOARD CONVERTIBLE TO AN EVACUATION CENTER PARTITION BY PARTICIPATIVE DESIGN METHOD
}

\author{
${ }^{1}$ Danilo V. RAVINA, ${ }^{2}$ Marc Christian Y. RUZ, ${ }^{3}$ Rowell Ray Lim SHIH \\ ${ }^{4}$ István KISTELEGDI \\ ${ }^{1,2,3}$ Breuer Marcel Doctoral School, Faculty of Engineering and Information Technology \\ University of Pecs, Boszorkany u. 2, H-7624 Pecs, Hungary and \\ Department of Architecture, School of Architecture, Fine Arts and Design \\ University of San Carlos Technological Center, Cebu City, Cebu, Philippines \\ e-mail: ${ }^{1}$ dravina@yahoo.com, ${ }^{2}$ ruz.architecture@gmail.com, ${ }^{3}$ rowellshih@yahoo.com \\ ${ }^{4}$ Department of Building Structures and Energy Design, Faculty of Engineering and \\ Information Technology, University of Pécs, Boszorkany u. 2, H-7624 Pécs, Hungary \\ e-mail: kistelegdisoma@mik.pte.hu
}

Received 8 September 2017; accepted 23 December 2017

\begin{abstract}
Evacuation centers play a vital role for natural disaster-prone countries like the Philippines. In the Philippines, a public school building serves as temporary evacuation centers for the displaced families. This study presents the design and methodology of blackboard modular furniture that can be converted to an emergency partition and storage for emergency provisions. These modular partitions provide a sense of privacy for each of the affected families, which are needed in any evacuation centers, particularly on the sick, aged, menstruating women and lactating mothers, among others. By using the participative design method, the design will therefore ensure user acceptability by the stakeholders. The resulting design allows for adaptability and portability, which therefore reduce material waste and cost. The final design was the product of the both participatory design approach while following the guidelines of the Department of Education of the Philippines.
\end{abstract}

Keywords: Disaster risk reduction, Emergency school furniture, Evacuation center partition, Multi-purpose, Modular

\section{Introduction}

Natural disasters like typhoons and earthquakes usually result in an enormous number of evacuees staying in evacuation centers for a significant amount of time [1]. These conditions also pose major public health challenges and people living in an evacuation area are more prone to diseases since they are overcrowded [2]. Elderly men and women, especially the ones with multiple chronic conditions, are particularly at risk in an evacuation center [3], [4], [5]. Individuals of low socio-economic status, mental illness or disabilities are the other vulnerable populations, which experience high 
mortality during disasters [6]. Furthermore, disaster evacuation centers require stocks of essential supplies and emergency equipment [1], which can be in short supply especially in disaster-prone countries in Southeast Asia. On 8 November 2013 typhoon Haiyan, considered to be the strongest tropical cyclone ever recorded, devastated parts of Bantayan Island in Cebu. After the onslaught of the typhoon, the government of the Philippines sought international assistance and one of these organizations was Caritas Switzerland. Caritas Switzerland focused their resources on rehabilitating schools, which were heavily devastated by the typhoon. The independent aid agency has been active in seven locations in Madridejos including the Kinatarkan Islands. The agency has so far rebuilt schools in the town of Pili, Malbago, Talangnan, Mancilang, Kaonkid, Bunakan and Hagdan. Since public schools in the Philippines are being used as temporary evacuation centers (Fig. 1), the main objective of Caritas Switzerland is to therefore build typhoon resilient schools. Caritas also intended to provide necessary interior furniture that can also be converted into evacuation center furniture. Marcel Reymond, country director of the Humanitarian Aid Department of Caritas Switzerland, approached the office of the Institute of Planning and Design (IPD) of the School of Architecture, Fine Arts and Design (SAFAD) of the University of San Carlos-Cebu for possible partnership.

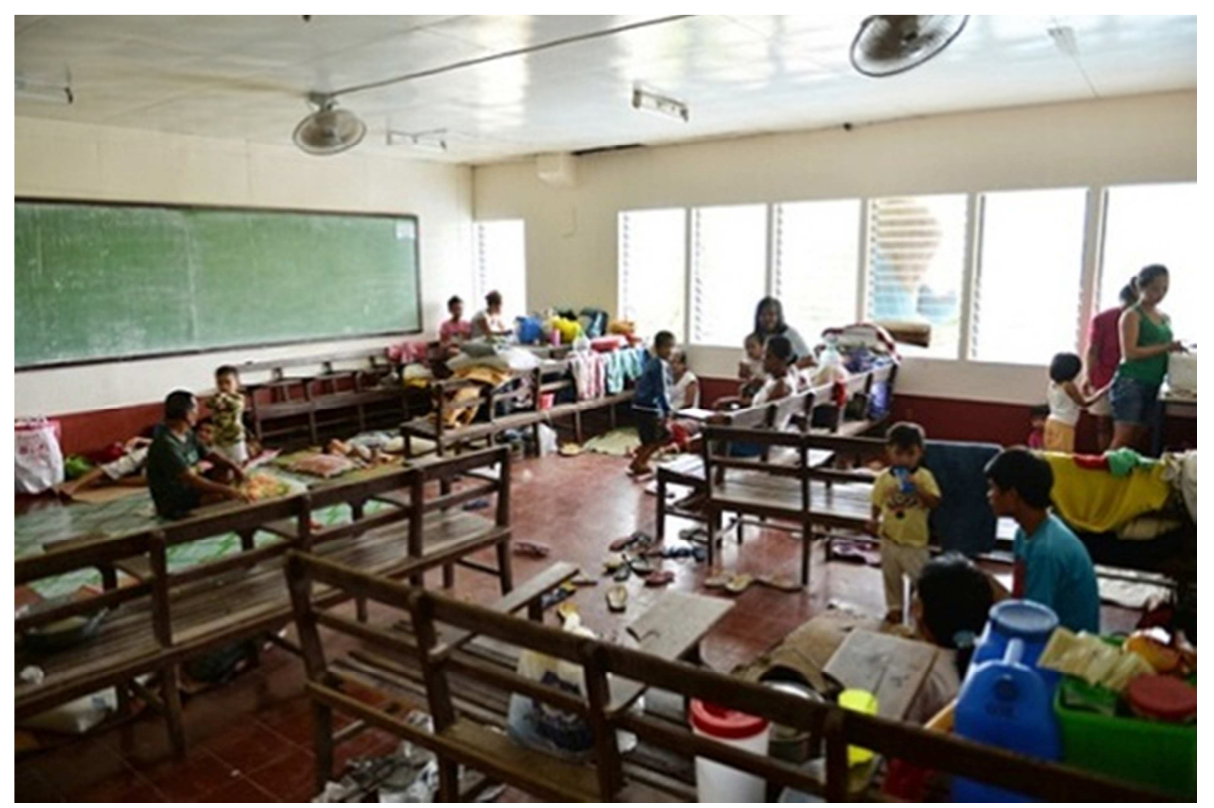

Fig. 1. An elementary school classroom in the Philippines being used as an evacuation center

There are two objectives of this study: First is the concept, design and prototype development of multi-purpose blackboard modular furniture that can be used inside the classrooms for an elementary school. During regular classes, the blackboard functions as a classroom media for learning. However, when the school is used as an evacuation 
center during disasters, this furniture functions as a partition inside the classroom to provide privacy that is greatly needed in any evacuation centers. Second is to permit participation of the stakeholders in the design of the furniture in order to ensure acceptability and acceptance. From the literature, it shows that in post-disaster situations there is a disconnection between the international humanitarian community and the people receiving assistance [7], [8]. Therefore, there must be a need for a more localized approach to the needs of the community. The facilitators then propose to encourage the involvement of the community to share ideas, knowledge and solve problems in a collaborative situation.

\section{Research methodology}

Two methodologies were used in the design and construction of the proposed blackboard furniture. First, the authors use the descriptive method of research. This involves the collection of data that provide information of the condition or actual situation through literary research and document analysis from various sources. The size of the blackboard must follow the guidelines of the Philippines Department of Education (PDE) manual. The revised edition of the 2007 Handbook on Educational Facilities Integrating Risk Reduction in School Construction was followed as guide for the designers of the Bakwitanan, a vernacular word, which means to 'evacuate to a safe place'. Second, the Participatory Design methodology was used in order to determine the user acceptance of the Bakwitanan. Participatory Design has been defined as ' $a$ strong commitment to understanding practice, guided by the recognition that designing the technologies people use in their everyday activities shapes, in crucial ways, how those activities might be done' [9]. The central idea in the methodology of Participatory Design is that those who are affected by what is designed should actively participate in the design process [10], [11]. Community participation allows an increasing use of the product and creates a sense of community between the users. It is therefore significant that the users should take an active role in the design of the final product for their own use [12]. In order to achieve this methodology, the authors organized and conducted a participatory workshop discussion in order to encourage the involvement of the stakeholders. By including the actual users in the design process, there is more user acceptance of the final prototype while reducing actual cost [13], [14]. In this study, a Focus Group Discussion (FGD) was organized between the stakeholders (parents, teachers and students) and the facilitators. Participants of the FGD were encouraged to provide design and implement ideas based on their personal experience and use. The authors explained the design and purpose of the emergency furniture to the stakeholders while feedbacks and comments were collected from them. The data was synthesized by the authors in order to serve as a guide in improving and refining the design of the Bakwitanan. With the financial assistance of Caritas Switzerland, an actual prototype was manufactured while the authors documented how the furniture was being used by the users for a period of six months. This process shows the complete research conceptual framework for the proposed Bakwitanan emergency furniture (Fig. 2). 


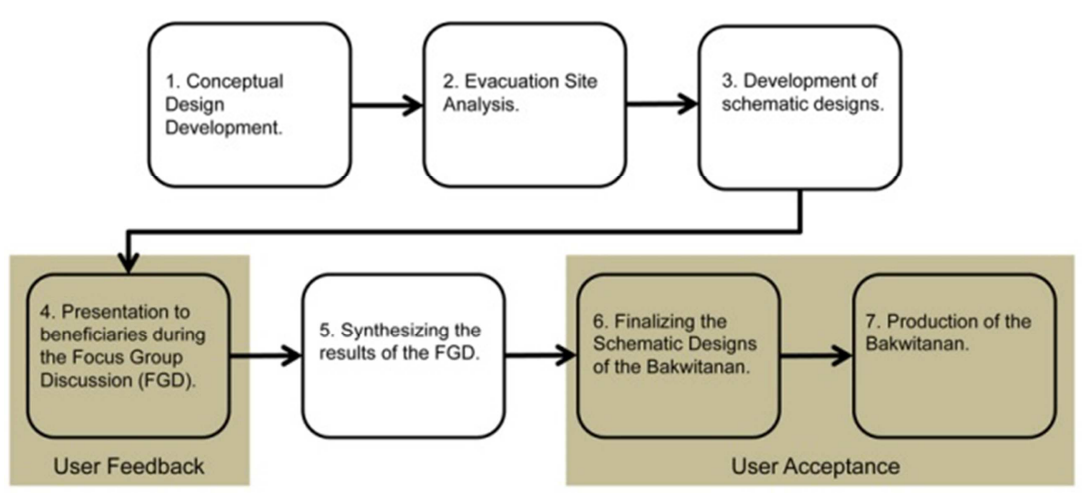

Fig. 2. The research conceptual framework

\subsection{Conceptual design development stage}

In the conceptual design stage of the Bakwitanan, the authors considered six design parameters (Table I) that served as frameworks for the authors on the outcome of the proposed project. First, the furniture must be adaptable in order to increase its cost-tobenefit ration as an evacuation center partition. Second, the furniture must be modular in order to avoid waste due to the limits of the basic material available in the Philippines, which is plywood. Third, the simplicity of the proposed furniture is important as only local manpower, simple tools and locally sourced materials are needed in the construction. Fourth, the furniture must be stable without any complicated moving parts. This will allow less expensive hardware and reduces future maintenance cost. Fifth, the blackboard furniture must be portable. In the event when after the classroom is used as an evacuation center, the furniture can be easily be arranged in different configurations or be transferred outside the classroom and used as emergency partitions or storage bin. Sixth, the standard height and length of the blackboard furniture must follow the standard Philippines Department of Education Facilities Manual (PDFM). This will avoid problems while ensuring that the Bakwitanan will fit into a standard Philippine public classroom. Finally, in order to increase user acceptability, the authors presented the schematic design to the community and formed a FGD in order to improve the design of the Bakwitanan. The final design allows increased satisfaction and thus minimizes rejection.

Table I

The proposed design parameters of the Bakwitanan

\begin{tabular}{|c|}
\hline Adaptability \\
Modularity \\
Simplicity \\
Stability \\
Portability \\
Standard height and length \\
\hline
\end{tabular}




\subsection{Evacuation site analysis}

Site observations and studies from previous evacuation sites were being analyzed and the Philippines Department of Education Facilities manual was being used as technical guidelines. The manual states that school buildings can be used as an evacuation site as a last resort during calamities and be used no more than 15 days. Despite this limited regulation, local government authorities, especially in far provinces, agree that only schools are large enough to handle these types of emergency situations. Furthermore, the manual states that the elevation height for elementary and secondary classroom blackboards should be $650 \mathrm{~mm}$ and $750 \mathrm{~mm}$ from the ground respectively. While there is almost zero privacy for the families who are living in an evacuation area, the authors have also observed how the evacuees have to use the classroom desk and chairs as temporary beds. In this regard, the ones who are most affected by this situation are the sick, aged, menstruating women, children and lactating mothers.

\subsection{Development of schematic design}

The modular shelving system proposed by the authors contains shelves in one face and a blackboard on the other face. During regular days the furniture is attached along the perimeter walls of the classroom and is used as furniture for learning purposes. However, when in used during disasters, the furniture can be removed from the walls and arranged to become partitions for evacuees (Fig. 3). By examining the dimensions of a standard Philippine classroom (7000 mm x $9000 \mathrm{~mm}$ ), eight modular furnitures can be attached to three perimeter walls.

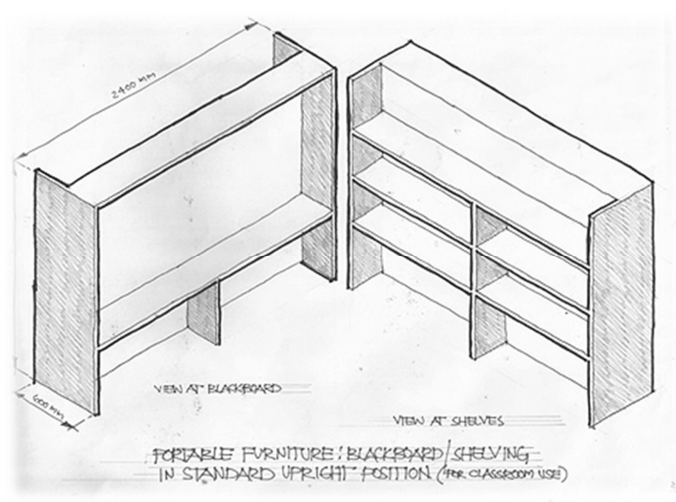

Fig. 3. Initial sketch of a schematic design of the Bakwitanan

The fourth wall, where the windows are located, can be left unused for natural day lighting and natural ventilation. The side where the blackboard is located will face the classroom, while the side where the shelves are located shall contain the curtains, sleeping mats and survival kits. When the classroom is used as a temporary evacuation center, the modular shelving furniture can be arranged for medium density occupancy specifically for delicate groups like the young orphans, sick and the aged. Additionally, 
the arrangement may also apply as treatment partitions for medical and dental missions during disasters (Fig. 4). A common area is provided as a communal space that encourages interaction between the groups. During natural disasters, social interactions between groups are essential as this will encourage a sense of belonging [15].

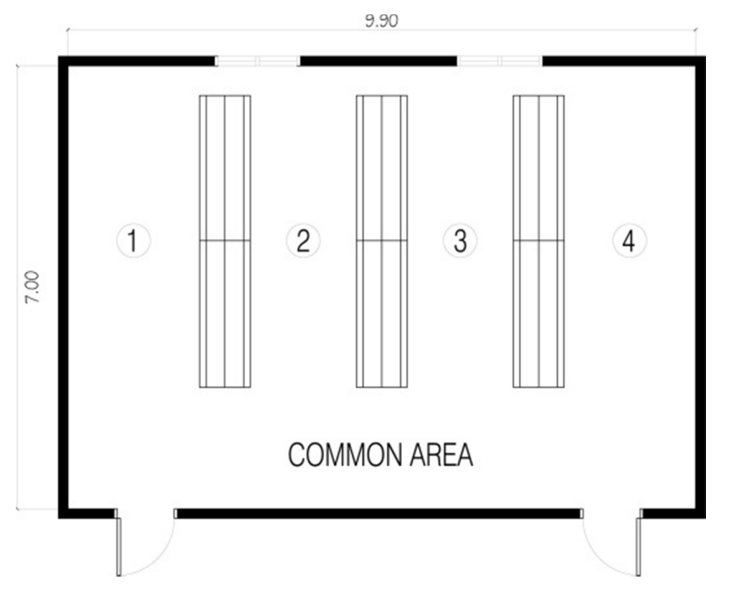

Fig. 4. The proposed layout of the Bakwitanan with a communal space

\subsection{Presentation to beneficiaries during the focus group discussion}

The schematic design of the proposed Bakwitanan was presented to the beneficiaries and stakeholders (15 students, 5 teachers and 10 parents) during the Focus Group Discussion in the Town of Pili Elementary School (Fig. 5). After the presentation, stakeholders convene and gave their assessment of the schematic designs of the proposed Bakwitanan. Additionally, the authors also presented a photograph of the prototype in order to get a sense of scale of the actual furniture when it is constructed (Fig. 6).

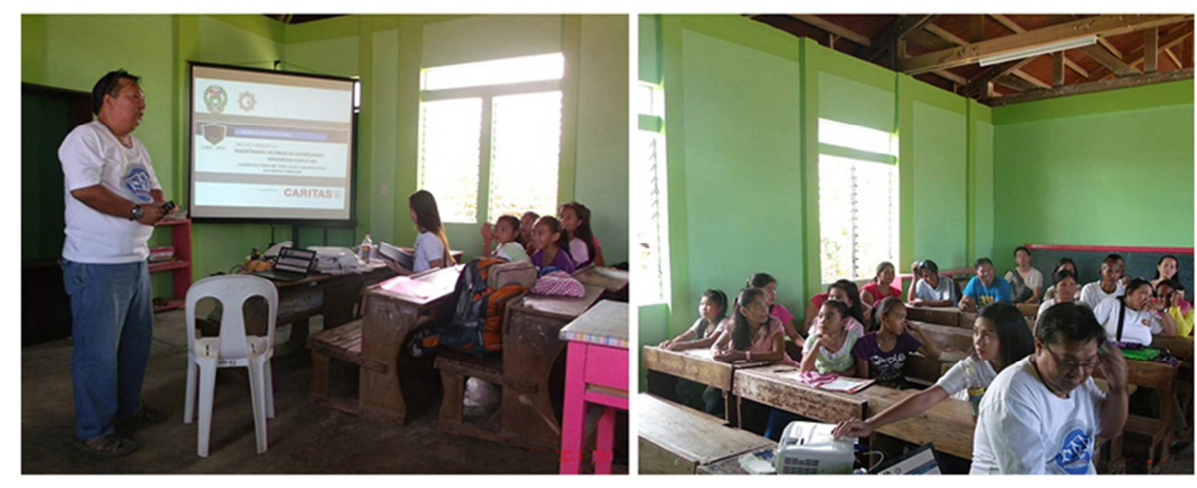

Fig. 5. The presentation of the proposed schematic designs of the Bakwitanan to the stakeholders of the Pili Elementary School 

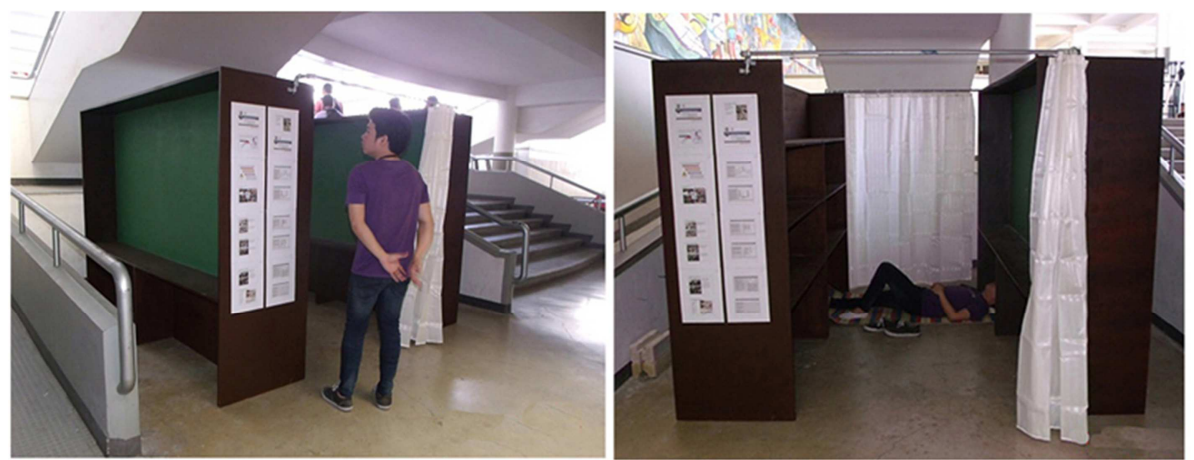

Fig. 6. The actual prototype of the Bakwitanan shown to the stakeholders

\subsection{Synthesizing the results of the focus group discussion}

Data was collected and the authors synthesized (Fig. 7a) all the recommendations and suggestions of the Focus Group Discussion (FGD). The feedbacks from the FGD recommended a number of design improvements, among them are:

(1) Curving the ends of the blackboard to improve visibility for the students;

(2) The addition of guidelines on the blackboard to improve writing accuracy for the teachers;

(3) The addition of storage space for chalk and erasers;

(4) The use simple materials like plywood which can be sourced locally; and

(5) The addition of sliders in order to easily move the blackboard into different desired configurations.

The authors then accumulate all the FGD comments and with the assistance of Caritas Switzerland (Fig. 7 b) redesigned the proposed schematic diagrams in line with the recommendations of the stakeholders.

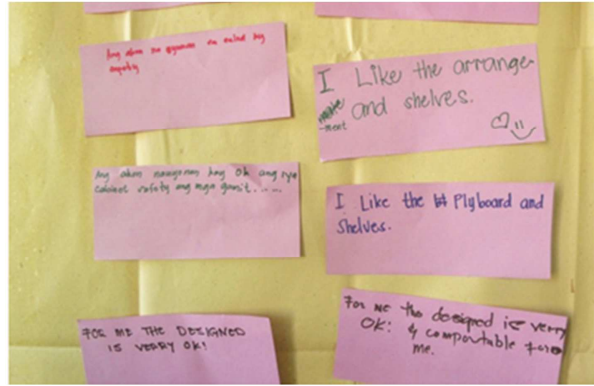

a)

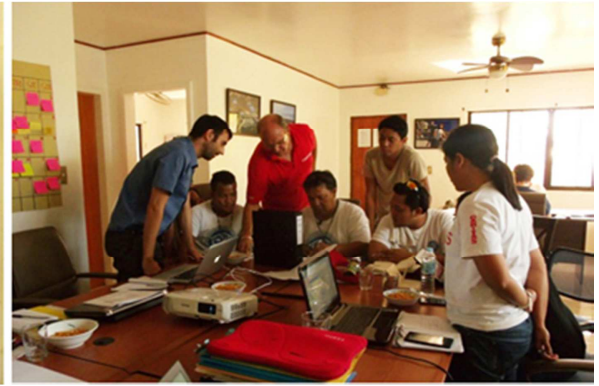

b)

Fig. 7. a) The recommendations and suggestion lists of the stakeholders; and b) the designers and authors accumulate and analyzed the given data 


\subsection{Finalizing the schematic design of the Bakwitanan}

A scale model (Fig. 8) was generated by the authors in order to easily visualize the final project. Following the recommendations given during the FGD, the architects and members of Caritas Switzerland agreed that the design of the Bakwitanan will be composed of three modules:

Module A (Fig. 9) comprises the left component with a curved surface;

Module B (Fig. 10) comprises the central portion which has a flat surface; and finally

Module C (Fig. 11) comprises the right component with a curved surface.

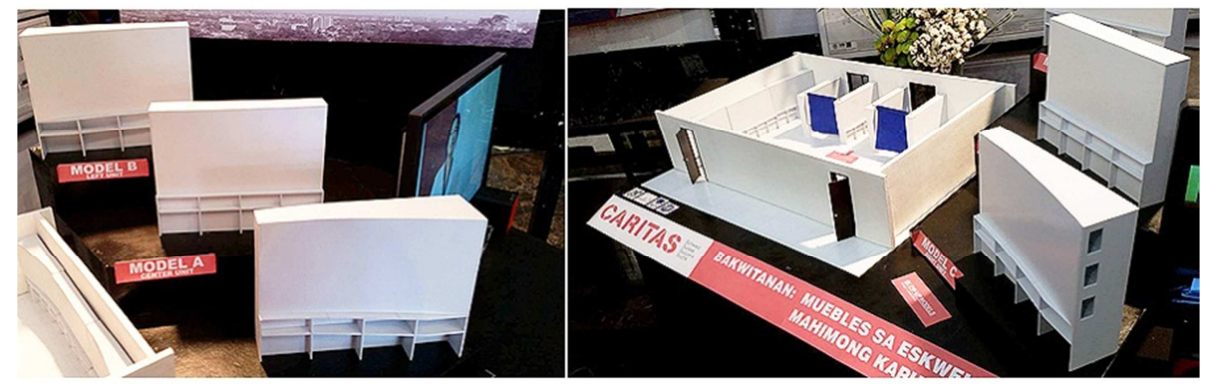

Fig. 8. Scale model of the three modules of the Bakwitanan

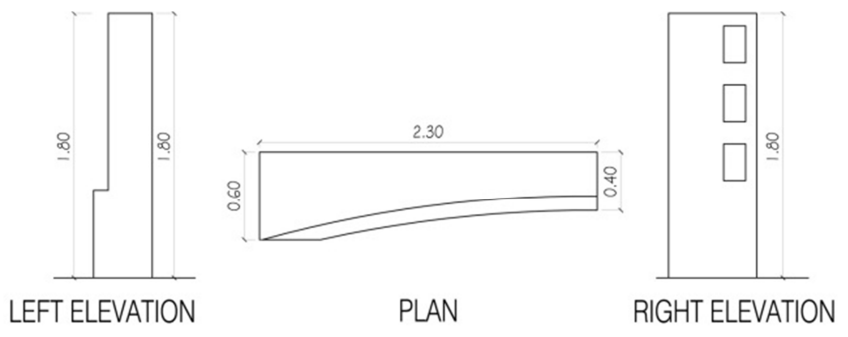

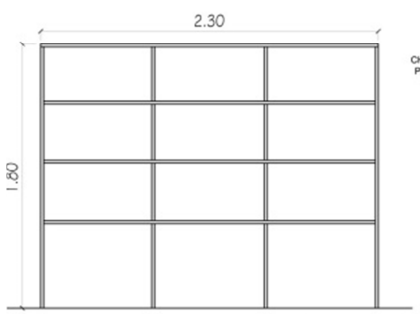

REAR ELEVATION

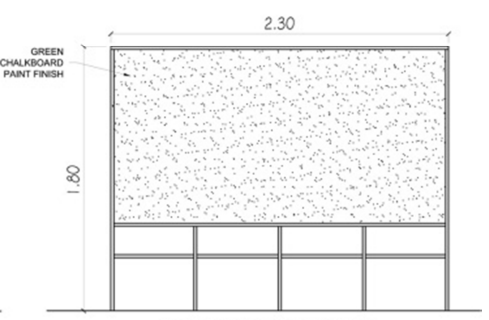

FRONT ELEVATION

\section{MODULE A}

Fig. 9. Technical details for Module A (Left side) of the Bakwitanan 

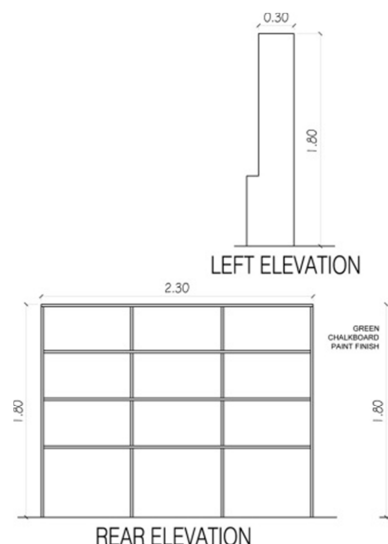

REAR ELEVATION

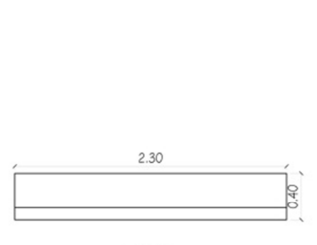

PLAN

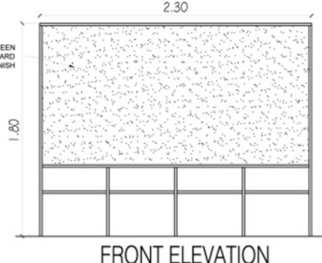

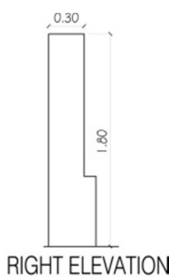

VATION

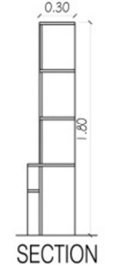

\section{MODULE B}

Fig. 10. Technical details for Module B (Center portion) of the Bakwitanan
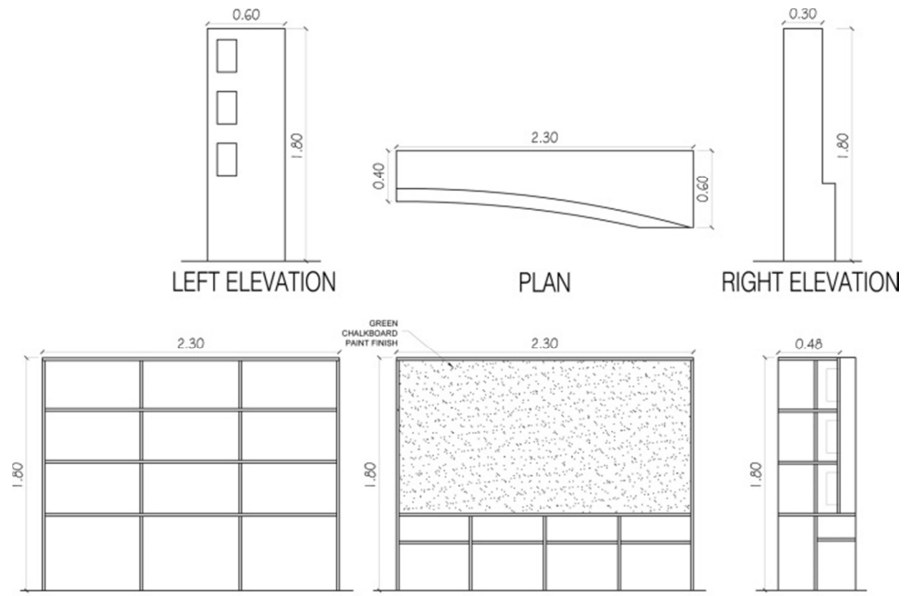

FRONT ELEVATION

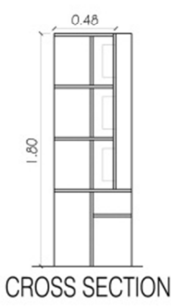

\section{MODULE C}

Fig. 11. Technical details for Module C (Right side) of the Bakwitanan

The three modules can be easily assembled, with the addition of sliders, to form a curvilinear blackboard. By separating the entire furniture into three modules, these can easily be adapted and configured into different layouts according to the needs of the affected families. The Bakwitanan used the standard $19 \mathrm{~mm}$ thick marine plywood, which can be sourced locally, thus cutting transportation cost during construction. The Bakwitanan also conforms to the DE standard dimensions of $4880 \mathrm{~mm}$ long x $1800 \mathrm{~mm}$ high and locks into place forming stable furniture. The final design is therefore in conformity with the proposed design parameters framework specified in Table I. 


\subsection{Production of the Bakwitanan}

A team of three carpenters was able to produce two sets of Bakwitanan in three days. The Bakwitanan was used as a blackboard during class hours with the additional three cabinets on the side of the blackboard (Fig. 12a), thus making use of the cavity of the curved surface. In Fig. $12 b$ and Fig. 13a, is shown how the Bakwitanan used as partitions when the classroom is used as temporary evacuation center. The front view of the finished Bakwitanan (Fig. 13b) with the added guidelines on the board as recommended during the FGD discussion. The completed classroom equipped with the Bakwitanan in Malbago Elementary School was formally turned over to the Local Government Unit (LGU's) officials. The total cost (as of March 2016) in the production of the Bakwitanan was US \$340, which comprises labor and materials. The resulting technical details and plans were presented to the Philippine Department of Education so that they can produce more emergency partitions in the future. Currently, the authors plan to bring the cost down by exploring other alternative materials and pursue financial assistance through different local and international donations.

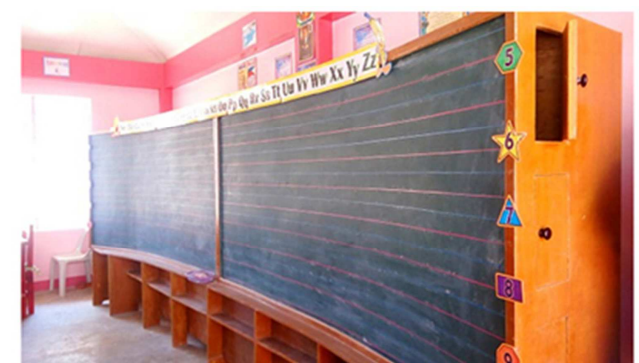

a)

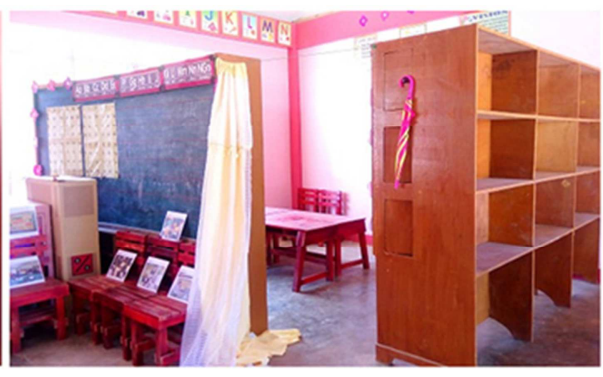

b)

Fig. 12. a) The Bakwitanan used as a blackboard during normal situations. Note the cabinets on the side of the blackboard; b) The Bakwitanan used as partitions inside the classroom

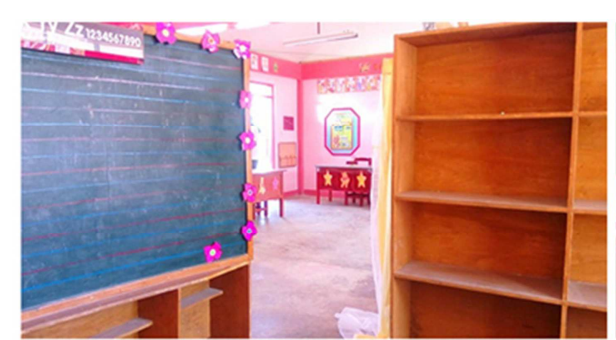

a)

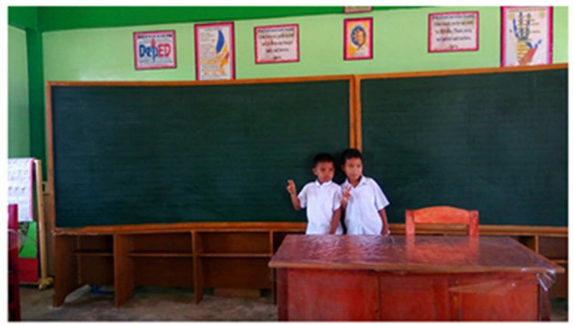

b)

Fig. 13. a) View from the inside of the Bakwitanan. Note the recommended lines on the blackboard; and b) the front view of the Bakwitanan 


\section{Conclusion}

This study demonstrated the concept, design and prototype of blackboard furniture that can be converted into an evacuation center partition for the victims of natural and man-made disasters in the Philippines. This study also showed how the Participative Design methodology through Focus Group Discussions from the users (teachers, students and parents) proved to be very useful to arrive in the final design of the furniture. Useful recommendations like putting lines on the blackboard, installing plastic sliders at the base of the furniture for easy transportation, and blackboards should be curved on the sides so that the students can have a better view promote community participation and design acceptance. Participatory Design proved to be useful in investigating design challenges while engaging the designers and the stakeholders. While this method itself is not new, its application in architecture, especially community restoration after a disaster, opens up other promising possibilities. Allowing community participation in planning and design creates an impact of increasing use of the product. Participatory Design is therefore significant to ensure user acceptability and satisfaction of any design. Finally, further investigation can be made in future studies to determine the level of performance of the Bakwitanan to various conditions experienced in other evacuation centers.

\section{Acknowledgements}

This work has been undertaken as a part of a project founded by the University Of San Carlos School Of Architecture, Fine Arts and Design (SAFAD), the Institute of Planning and Design (IPD) with the assistance of Caritas Switzerland.

\section{References}

[1] Ranghieri F., Ishiwatari M, (Eds) Learning from mega disasters: Lessons from the Great East Japan Earthquake, World Bank Publications, 2014.

[2] Toole M. J., Waldman R. J. The public health aspects of complex emergencies and refugee situations, Annual Review of Public Health, Vol. 18, No. 1, 1997, pp. 283-312.

[3] Bierman A. S., Clancy C. M. Health disparities among older women: identifying opportunities to improve quality of care and functional health outcomes, J. Am. Med. Womens Assoc. Vol. 56, No. 4, 2001, pp. 155-159, p. 188.

[4] Menotti A., Mulder I., Nissinen A., Giampaoli S., Feskens E. J., Kromhout D. Prevalence of morbidity and multimorbidity in elderly male populations and their impact on 10-year all-cause mortality: The FINE study (Finland, Italy, Netherlands, Elderly), J. Clin. Epidemiol, Vol. 54, No. 7, 2001, pp. 680-686.

[5] Fernandez L. S., Byard D., Lin C. C., Benson S., Barbera J. A. Frail elderly as disaster victims: emergency management strategies, Prehospital Disaster Med. Vol. 17, No. 2, 2002, pp. 67-74.

[6] Mensah G. A., Mokdad A. H., Posner S. F., Reed E., Simoes E. J., Engelgau M. M. When chronic conditions become acute: prevention and control of chronic diseases and adverse health outcomes during natural disasters, Preventing Chronic Disease. Spec. No. 2, 2005, Paper No. PMC1459465. 
[7] Field J. What is appropriate and relevant assistance after a disaster? Accounting for culture(s) in the response to Typhoon Haiyan/Yolanda, International Journal of Disaster Risk Reduction, Vol. 22, 2017, pp. 335-344.

[8] Ravina D., Shih R.1 R.. A shelter for the victims of the Typhoon Haiyan in the Philippines: The design and methodology of construction, Pollack Periodica, Vol. 12, No. 2, 2017, pp. 129-139.

[9] Robertson T., Simonsen J. Challenges and opportunities in contemporary participatory design, Design Issues, Vol. 28, No. 3, 2012, pp. 3-9.

[10] Gershon R. R. M., Rubin M. S., Qureshi K. A., Canton A. N., Matzner F. J. Participatory action research methodology in disaster research: results from the World Trade Center evacuation study, Disaster Medicine and Public Health Preparedness, Vol. 2, No. 3 2008, pp. $142-149$.

[11] Aysan Y., Davis I. (Eds) Disasters and the small dwelling, Perspectives for the UN IDNDR, James \& James, London, 1992.

[12] Turan S. Ö., Pulatkan M., Beyazli D., Özen B. S. User evaluation of the urban park design implementation with participatory approach process, Procedia-Social and Behavioral Sciences, Vol. 216, 2016, pp. 306-315.

[13] Na J. I. The Yonmenkaigi system method for disaster restoration of a local community in Korea, Procedia-Social and Behavioral Sciences, Vol. 218, 2016, pp. 76-84.

[14] Bjögvinsson E., Pelle E., Per-Anders H. Design things and design thinking: Contemporary participatory design challenges, Design Issues, Vol. 28, No. 3, 2012, pp. 101-116.

[15] Quarantelli E. L. Disaster crisis management: A summary of research findings, Journal of Management Studies, Vol. 25, No. 4, 1988, pp. 373-385. 